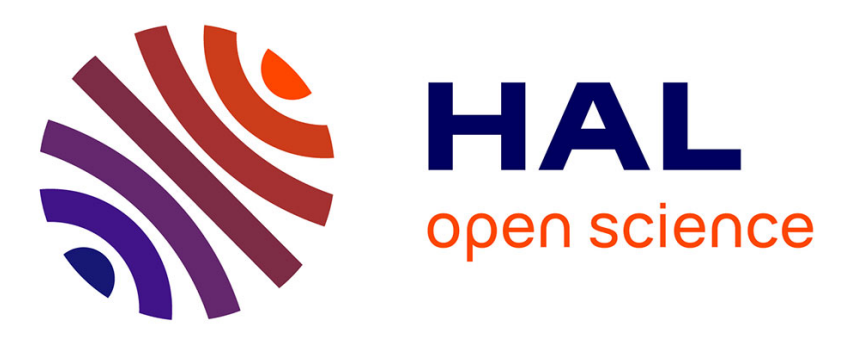

\title{
Identification of non-homogeneous stress fields in dynamic experiments with a non parametric method
}

\author{
Ramzi Othman, Souheila Aloui, Arnaud Poitou
}

\section{To cite this version:}

Ramzi Othman, Souheila Aloui, Arnaud Poitou. Identification of non-homogeneous stress fields in dynamic experiments with a non parametric method. Polymer Testing, 2010, 29 (5), pp.616-623. 10.1016/j.polymertesting.2010.03.013 . hal-01006941

\section{HAL Id: hal-01006941 \\ https://hal.science/hal-01006941}

Submitted on 22 Jan 2017

HAL is a multi-disciplinary open access archive for the deposit and dissemination of scientific research documents, whether they are published or not. The documents may come from teaching and research institutions in France or abroad, or from public or private research centers.
L'archive ouverte pluridisciplinaire HAL, est destinée au dépôt et à la diffusion de documents scientifiques de niveau recherche, publiés ou non, émanant des établissements d'enseignement et de recherche français ou étrangers, des laboratoires publics ou privés.

\section{(c)(1)}

Distributed under a Creative Commons Attribution| 4.0 International License 


\title{
Identification of non-homogeneous stress fields in dynamic experiments with a non-parametric method
}

\author{
Ramzi Othman, Souheila Aloui, Arnaud Poitou \\ Institut de Recherche en Génie Civil et Mécanique, Ecole Centrale de Nantes, 1 Rue de, la Noë BP 92101, F-44321 Nantes cedex 3, France
}

\begin{abstract}
Stress and strain fields are generally assumed homogeneous in high strain rate experi-ments. Therefore, only mean stress and strain are measured. However, this assumption is not valid for soft materials and/or very high strain rates. For heterogeneous dynamic tests, inverse techniques are usually proposed to identify the stress and strain fields. In this paper, a non-parametric method to identify the stress field is presented. This method is based on a force measurement on the specimen boundary and a displacement (strain) field measurement carried out by a digital image correlation technique. It is applied to measure the strain rate sensitivity of a synthetic rubber (Criblex 80). This new technique estimates the stress field with good accuracy.
\end{abstract}

Keywords: Rubber, Dynamic equilibrium, High-strain rate, Soft materials, Digital image correlation (DIC)

\section{Introduction}

In several engineering applications (automobile, aerospace, civil engineering, forming processes, etc.), the structures used can undergo intermediate to high strain rate loadings. In order to design structures that can withstand this kind of loads, constitutive equations, which take into account strain rate sensitivity, are highly appreciated. Consequently, several methods have been developed since the beginning of the 20th century for measuring the stressstrain relationship over a wide range of strain rates. For instance, we can cite servo-hydraulic machines [1-3], drop weight towers [4], split Hopkinson bars [5-9] and slow bars [9-12]. For an extensive review of these techniques, the reader is referred to [13].

In order to develop or identify material constitutive equations, the stress-strain relation should be measured. In the above methods, the stress and strain in a specimen are mostly recovered from boundary measurements. Precisely, the stress is recovered from a force measurement recorded at a sample end. Similarly, the strain is deduced from a displacement recorded at the same or different sample side. This is possible as far as the assumption of homogeneous stress and strain fields is valid $[14,15]$. In the case of stress or strain heterogeneity, the conventional recovery of stress and strain may lead to significant inaccuracies [16-18].

In the case of dynamic testing of metals, the stress and strain homogeneity is rapidly achieved. This is mainly due to high mechanical wave speeds. Indeed, the dynamic equilibrium is established after a few wave round-trips in the specimen. On the contrary, soft materials have low mechanical wave speeds. Consequently, the dynamic equilibrium is belatedly achieved [18-21]. Considering, for example, a rubber-like material (Young's modulus $E_{r}=10 \mathrm{MPa}$ and density $\rho_{r}=1000 \mathrm{~kg} / \mathrm{m}^{3}$ ), the axial elastic wave speed is equal to $C_{r}=\sqrt{E_{r} / \rho_{r}}=100 \mathrm{~m} / \mathrm{s}$. Therefore, the wave takes $\Delta t=L_{s} / C_{r}=50 \mu$ s to go through a sample of length $L_{s}=5 \mathrm{~mm}$. At a strain rate of $\dot{\varepsilon}=1000 / \mathrm{s}$, some sample parts achieves a strain $\varepsilon=\dot{\varepsilon} \tau \approx 5 \%$. In other words, some parts of the sample can be strained to $5 \%$ while the sample end is not strained at all. Assuming that the dynamic equilibrium is obtained after three round-trips of the wave, some parts of the sample are strained up to $30 \%$ to achieve dynamic equilibrium. In line with this, Sarva et al. [22] presented a dynamic test on polyurea at a strain rate of $7500 / \mathrm{s}$ 
where the dynamic equilibrium is achieved after the specimen is strained by $35 \%$.

It follows from the above example that several parameters can accelerate or retard the establishment of the dynamic stress and strain homogeneity: the material stiffness and density, the sample length and the strain rate. In addition, it was demonstrated that loading rise-time has an influence on the dynamic homogeneity achievement. The higher the rise-time, the faster the homogeneity is achieved.

Pulse shaping or flat samples can help fast achievement of homogeneity in the specimen [23,24]. However, pulse shaping depends on the material behaviour. On the other hand, the use of flat samples may raise some limitations [25], mainly due to friction. Generally, the assumption of homogeneity is not valid when testing soft materials and/ or at high strain rates. However, the investigation of strain rate sensitivity of soft materials is a main concern in many engineering applications [22,26-29], for example to design aircraft structures to withstand tyre debris impact [30].

In order to resolve the heterogeneity problem under quasi-static conditions, inverse techniques have been adopted (see for example Ref. [31]). These techniques were also applied to dynamic experiments [32-37]. Nevertheless, the main problem with inverse techniques is that a constitutive equation should be known beforehand. Mousavi et al. [38] proposed a non-parametric method. However, their solution is limited to visco-elastic materials. In this paper, we propose a non-parametric solution for measuring heterogeneous stress field in uni-axial dynamic experiments. The axial stress is recovered from the displacement field (measured by digital image correlation) and a force measurement on the boundary. This technique is applied to measure the stress field in synthetic rubber at three different strain rates.

\section{Theoretical basis}

In this work we are concerned with uni-axial compressive dynamic experiments. The developed approach can be extended easily to tensile dynamic experiments. The geometry of a specimen of length $\mathrm{L}$ is shown schematically in Fig. 1. In this figure, a square crosssection is considered. However, the present method deals with any initial cross-section which is constant along the $\underline{e}_{1}$ direction. Below, $A_{\mathrm{o}}$ holds for the initial cross-sectional area. Let $\Omega(t)$ be the domain occupied by the tested specimen during the test. Each point in $\Omega(t)$ is represented by its position $\underline{\mathrm{X}}=X_{1} \underline{\mathrm{e}}_{1}+X_{2} \underline{\mathrm{e}}_{2}+X_{3} \underline{\mathrm{e}}_{3}$ in the initial configuration $\Omega(t)=\Omega_{0}$.

As we are concerned with uni-axial compression tests, we assume that:

- cross-sections remain plane during the test, and

- forces are applied normally to any cross-section and only depend on the longitudinal space abscissa.

Let $S_{\chi}=\left\{\underline{\mathrm{X}} \in \Omega_{0} ; \underline{\mathrm{X}} . \underline{\mathrm{e}}_{1}=\chi\right\}$ be the cross-section of normal $\underline{\mathrm{e}}_{1}$ at X1$=\chi$. It is assumed that the cross-sections $\mathrm{S}_{\chi}$ remain plane during the test. Hence, for any point $\underline{X}$ of the cross-section $S_{X_{1}}$, the following equation holds:

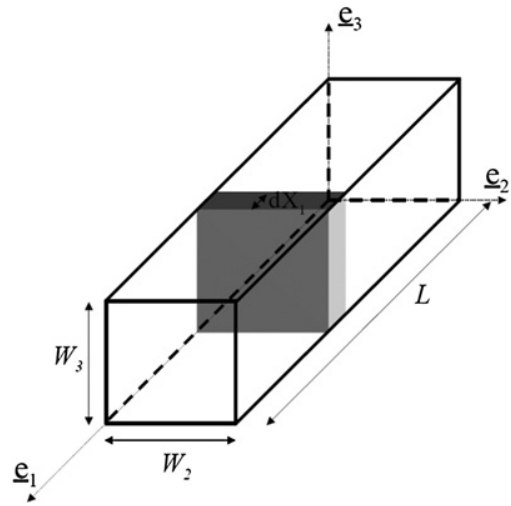

Fig. 1. Schematic of the specimen.

$\underline{u}(\underline{X}, t) \cdot \underline{e}_{1}=u_{1}\left(X_{1}, t\right)$

where $\underline{u}(\underline{X}, t)$ is the displacement field and $u_{1}$ is the displacement on $\underline{e}_{1}$, which only depends on the first spatial coordinate and time. Furthermore, we consider that the force applied to a cross-section $S_{X_{1}}$ is normal to it and only depends on $X_{1}$ and $t$. Consequently, this force is written:

$\underline{F}(\underline{X}, t)=F_{1}\left(X_{1}, t\right) \underline{e}_{1}$

We isolate a slice of the specimen of length $\mathrm{d} X_{1}$ (Fig. 1). Then we write the second Newton's law on $\underline{e}_{1}$ direction. This yields:

$F_{1}\left(X_{1}+d X_{1}, t\right)-F_{1}\left(X_{1}, t\right)=\rho_{0} A_{0} d X_{1} \frac{\partial^{2} u_{1}}{\partial t^{2}}\left(X_{1}, t\right)$

where $\rho_{0}$ is the initial material density and $A_{0}$ is the initial cross-sectional area of the specimen. Eq. (3) yields:

$\frac{\partial F_{1}}{\partial X_{1}}\left(X_{1}, t\right)=\rho_{0} A_{0} \frac{\partial^{2} u_{1}}{\partial t^{2}}\left(X_{1}, t\right)$

By integrating Eq. (4) along the specimen length, we obtain:

$F_{1}\left(X_{1}, t\right)=F_{1}(0, t)+\rho_{0} A_{0} \int_{\xi=0}^{\xi=X_{1}} \frac{\partial^{2} u_{1}}{\partial t^{2}}(\xi, t) d \xi$

This last equation is very interesting. It means that the force $F_{1}\left(X_{1}, t\right)$, applied to any cross-section $S_{X_{1}}$, is recoverable knowing the force at $F_{1}\left(X_{1}=0, t\right)$ and the acceleration field:

$\gamma_{1}\left(X_{1}, t\right)=\frac{\partial^{2} u_{1}}{\partial t^{2}}\left(X_{1}, t\right)$

The force applied at $X_{1}=0$ can be measured by any available force transducer or Hopkinson bar method. The acceleration field can be deduced from the displacement field which can be measured by digital image correlation (DIC), for example [36,39]. Therefore, Eq. (5) is a hopeful solution for heterogeneous dynamic experiments. Indeed, we can indentify the force applied to any cross-section of the specimen by measuring the displacement field and the force at one boundary. 
The stress field can be assumed uni-axial in dynamic compressive experiments. The Cauchy stress tensor is reduced to:

$\underset{=}{=}=\left(\begin{array}{ccc}\sigma_{11} & 0 & 0 \\ 0 & 0 & 0 \\ 0 & 0 & 0\end{array}\right)$

The non-zero component of the Cauchy stress tensor, also called the axial true stress, can be calculated by the following equation:

$$
\begin{aligned}
\sigma_{11}\left(X_{1}, t\right) & =\frac{F_{1}\left(X_{1}, t\right)}{A\left(X_{1}, t\right)} \\
& =\frac{F_{1}(0, t)}{A\left(X_{1}, t\right)}+\frac{\rho_{0} A_{0}}{A\left(X_{1}, t\right)} \int_{\xi=0}^{\xi=X_{1}} \frac{\partial^{2} u_{1}}{\partial t^{2}}(\xi, t) d \xi
\end{aligned}
$$

where $A\left(X_{1}, t\right)$ is the area of the cross-section $S_{X_{1}}$ at a time $t$. $A\left(X_{1}, t\right)$ can also inferred from the displacement field obtained by DIC. Therefore, Eq. (7) means that the true stress can also be indentified from the displacement field and a force measurement on one boundary.

$A\left(X_{1}, t\right)$ can be identified directly from the displacement field. In this paper, we will deduce $A\left(X_{1}, t\right)$ from the strain field. Mainly, we assume that the strain field is constant in a cross-section $S_{X_{1}}$, i.e., $e(\underline{X}, t)=e\left(X_{1}, t\right)$ and $\varepsilon(\underline{X}, t)=\varepsilon\left(X_{1}, t\right)$ where $e$ and $\varepsilon$ are the nominal and

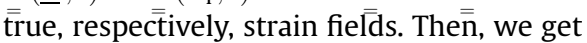

$A\left(X_{1}, t\right)=\left(1+e_{22}\left(X_{1}, t\right)\right)\left(1+e_{33}\left(X_{1}, t\right)\right) A_{0}$

In the case of an isotropic material, $e_{33}\left(X_{1}, t\right)=e_{22}\left(X_{1}, t\right)$. Hence, Eq. (8) is equivalently rewritten:

$A\left(X_{1}, t\right)=\left(1+e_{22}\left(X_{1}, t\right)\right)^{2} A_{0}$

As we are interested in heterogeneous dynamic experiments, we define the following coefficients in order to quantify the heterogeneity in the specimen:

$\alpha_{\sigma_{11}}(t)=\sqrt{\frac{\int_{0}^{L}\left|\sigma_{11}\left(X_{1}, t\right)-\left\langle\sigma_{11}\right\rangle(t)\right| d X_{1}}{\int_{0}^{L}\left|\left\langle\sigma_{11}\right\rangle(t)\right| d X_{1}}}$

$\alpha_{\varepsilon_{11}}(t)=\sqrt{\frac{\int_{0}^{L}\left|\varepsilon_{11}\left(X_{1}, t\right)-\left\langle\varepsilon_{11}\right\rangle(t)\right| d X_{1}}{\int_{0}^{L}\left|\left\langle\varepsilon_{11}\right\rangle(t)\right| d X_{1}}}$

where $\quad\left\langle\sigma_{11}\right\rangle(t)=\int_{0}^{L} \sigma_{11}\left(X_{1}, t\right) \mathrm{d} X_{1} / L \quad$ and $\left\langle\varepsilon_{11}\right\rangle(t)=\int_{0}^{L} \varepsilon_{11}\left(X_{1}, t\right) \mathrm{d} X_{1} / L$ are the spatial mean value of the axial true stress and strain, respectively. $\alpha_{\sigma_{11}}(t)$ represents the heterogeneity of the axial stress in the specimen. When $\alpha_{\sigma_{11}}(t)$ vanishes, the stress field is almost homogeneous and can be approximated by its mean value. Similarly, $\alpha_{\varepsilon_{11}}(t)$ represents the heterogeneity of the axial strain in the specimen. In the case of homogeneous strain field, $\alpha_{\varepsilon_{11}}(t) \ll 1$.

\section{Application to synthetic rubber}

\subsection{Method}

The non-parametric method was tested with a synthetic rubber (Criblex 80). Its density was equal to $1272 \mathrm{~kg} / \mathrm{m}^{3}$. Let
$L, W_{2}$ and $W_{3}$ be the sample length, width in $\underline{\mathrm{e}}_{2}$ direction and width in $\underline{e}_{3}$ direction, respectively. In our case $L=W_{2}=W_{3}=10 \mathrm{~mm}$. A speckle pattern was painted on a face of each sample in order to carry out digital image correlation (DIC). Three strain rates were considered: quasi-static, medium strain rate and high strain rate. We are concerned only with uni-axial compression tests.

\subsubsection{Quasi-static strain rates}

The quasi-static tests were realised on an INSTRON 5584 machine. The applied velocity was $0.6 \mathrm{~mm} / \mathrm{min}$ and the force measured with a piezo-electric transducer. This force, denoted as $F_{0}(t)$ was sampled at a frequency of $1 \mathrm{~Hz}$ which gives a step time of $\tau=1 \mathrm{~s}$.

The set-up was also instrumented with a video camera (PHOTRON Ultima APX). The resolution and the acquisition frequency were $512 \times 512$ pix $^{2}$ and 1 frame/s, respectively. These images were analysed by DIC software (ICASOFT 4.62). Therefore, we can infer the $2 \mathrm{D}$ displacement field at the filmed surface $S_{u}$ (see Fig. 2).

\subsubsection{Intermediate strain rates}

Intermediate strain rate tests were realised with an MTS 819 servo-hydraulic machine instrumented with a piezoelectric force transducer to measure the force at $X_{1}=0: F_{0}(t)$. The tests were carried out with a loading speed equal to $0.6 \mathrm{~m} / \mathrm{s}$. This machine was also instrumented with a high speed video camera (PHOTRON Ultima APX) with the acquisition frequency fixed at $10000 \mathrm{frame} / \mathrm{s}$ and a resolution of $128 \times 248 \mathrm{pix}^{2}$. The ICASOFT DIC software is then applied to analyse the obtained images and infer the 2D displacement and strain fields at $S_{u}$.

\subsubsection{High strain rates}

For high strain rate experiments, we used a directimpact Hopkinson bar (Fig. 3) [40,41]. As rubbers are soft materials, one should use low-impedance bars to increase signal-to-noise ratio. There are two possible solutions: polymeric [42] or hollow [43] bars. In our work, we used a hollow aluminium bar with inner and outer diameters of 14 and $16 \mathrm{~mm}$, respectively. This bar is instrumented with a strain gauge station in order to measure the transmitted wave $\varepsilon_{\text {tra }}(t)$. The output force reads:

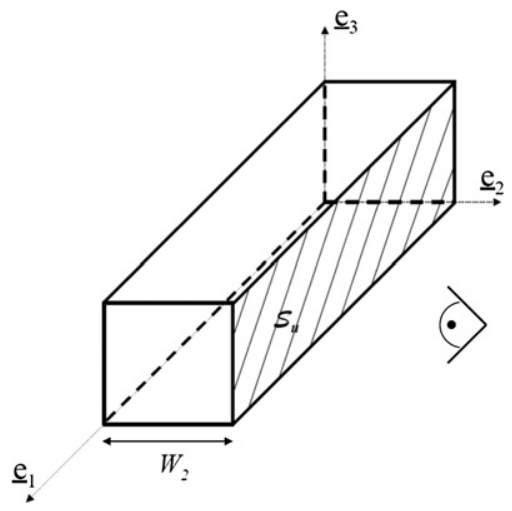

Fig. 2. Filmed surface. 


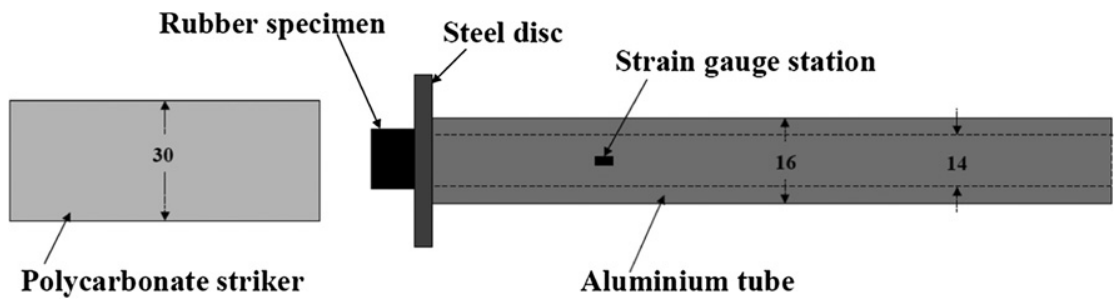

Fig. 3. Schematic of the direct-impact Hopkinson bar set-up.

$F_{\text {out }}(t)=E_{b} S_{b} \varepsilon_{0, t r a}(t)$

where $E_{b}$ and $S_{b}$ are the bar Young's modulus and crosssectional area, respectively, and $\varepsilon_{0, t r a}(t)$ the transmitted wave measured at the bar-specimen interface. This wave is deduced from the transmitted wave measured at the gauge station, $\varepsilon_{\text {tra }}(t)$, by wave shifting. Let $a$ be the distance between the gauge station and the bar-specimen interface. Hence, the Fourier components of the two transmitted waves are related by:

$\tilde{\varepsilon}_{0, \operatorname{tra}}(\omega)=\exp (i \xi(\omega) a) \tilde{\varepsilon}_{\text {tra }}(\omega)$

where $\xi(\omega)$ is the dispersion relation and $\tilde{f}$ is the Fourier transform of $f$. The dispersion is determined by a method exploiting the bar resonances developed in Ref. [44].

As the bar is hollow, a steel 5-mm thick disc is used in order that the force applied by the specimen is uniform on the bar cross-section. As the disc thickness is insignificant before the excited wavelengths, it should not alter wave propagation.

We choose the bar-specimen interface as the origin of the $\underline{\mathrm{e}}_{1}$ axis. Therefore, the force at the origin will be the output force:

$F_{0}(t)=F_{\text {out }}(t)$

The 2D displacement and strain fields are determined by DIC technique. The acquisition frequency is fixed at 100000 frame/s with a resolution of $128 \times 248 \mathrm{pix}^{2}$. Therefore, $\tau=10 \mu \mathrm{s}$.

\subsection{Analysis}

In the previous section, we detailed how we measured, for each set-up, a force at one of the specimen boundaries and a two-dimensional displacement (and strain) field(s). In this section, the stress field is calculated from these measured data. Subsequently, an error measure is defined.

\subsubsection{Stress field identification}

Let $u_{1}\left(X_{1} \underline{\mathrm{e}}_{1}+W_{2} \underline{\mathrm{e}}_{2}+X_{3} \underline{\mathrm{e}}_{3}, t\right)$ be the axial displacement field in the filmed surface. Similarly, let $\varepsilon_{22}\left(X_{1} \underline{\mathrm{e}}_{1}+W_{2} \underline{\mathrm{e}}_{2}+X_{3} \underline{\mathrm{e}}_{3}, t\right)$ be the second diagonal strain component in the surface. Subsequently, these twodimensional fields will simply be denoted $u_{1}\left(X_{1}, X_{3}, t\right)$ and $\varepsilon\left(X_{1}, X_{3}, t\right)$. The DIC software gives the Hencky strain (logarithmic strain). Then, the nominal strain is deduced by:

$e_{22}\left(X_{1}, X_{3}, t\right)=\exp \left(\varepsilon_{22}\left(X_{1}, X_{3}, t\right)\right)-1$
As we assume a one dimensional compressive test, we compute the average over the $\underline{\mathrm{e}}_{3}$ direction, of both $u_{1}\left(X_{1}, X_{3}\right.$, $t)$ and $e_{22}\left(X_{1}, X_{3}, t\right)$. We obtain,

$U_{1}\left(X_{1}, t\right)=\frac{1}{W_{3}} \int_{\xi=0}^{\xi=W_{3}} u_{1}\left(X_{1}, X_{3}, t\right) d X_{3}$

and

$E_{22}\left(X_{1}, t\right)=\frac{1}{W_{3}} \int_{\xi=0}^{\xi=W_{3}} e_{22}\left(X_{1}, X_{3}, t\right) d X_{3}$

We should note that we need to differentiate the displacement in Eq. (7) twice. In this work, the displacement is differentiated by a local polynomial interpolation method. For example, if we want to compute the acceleration at a time $t_{0}=j_{0} \tau$ and at $X_{1}$, i.e., $\Gamma_{1}\left(X_{1}, t\right)$, we consider $(2 n+1)$ values of the displacement: $U_{1}\left(X_{1},\left(j_{0}-n\right) \tau\right), \cdots, U_{1}\left(X_{1},\left(j_{0}+n\right) \tau\right)$. These $(2 n+1)$ points are then interpolated with a polynomial function of degree $m \leq 2 n$,

$P_{m, X_{1}}(t)=a_{0}+a_{1} t+\cdots+a_{m} t^{m}$

Subsequently, the polynomial function is differentiated twice:

$P_{m, X_{1}}^{(2)}(t)=2 a_{2}+6 a_{3} t+\cdots+m(m-1) a_{m} t^{m-2}$

Finally the acceleration reads:

$\Gamma_{1}\left(X_{1}, t_{0}\right)=P_{m, X_{1}}^{(2)}\left(t_{0}\right)$

Now, we get a force measurement at one boundary $\left(F_{0}(t)\right)$, the axial acceleration field $\left(\Gamma_{1}\left(X_{1}, t\right)\right)$ and the second diagonal nominal strain component $\left(E_{22}\left(X_{1}, t\right)\right)$. By applying Eq. (7) we can deduce the first diagonal Cauchy stress component:

$\Sigma_{11}\left(X_{1}, t\right)=\frac{F_{0}(t)+\rho_{0} A_{0} \int_{\xi=0}^{\xi=X_{1}} \Gamma_{1}(\xi, t) d \xi}{A_{0}\left(1+E_{22}\left(X_{1}, t\right)\right)^{2}}$

\subsubsection{Error measurement}

In this section, we detail a method to measure errors of the non-parametric method. The specimen material is homogeneous; therefore, the stress-strain relation should be the same at any point. With the DIC technique, we can get also the first component of the Hencky strain field: $\varepsilon_{11}\left(X_{1} \underline{\mathrm{e}}_{1}+W_{2} \underline{\mathrm{e}}_{2}+X_{3} \underline{\mathrm{e}}_{3}, t\right)$, which will be simply denoted $\varepsilon_{11}\left(X_{1}, X_{3}, t\right)$. As we assume a uni-axial compression test, we average over the $\underline{e}_{3}$ direction: 
$\varepsilon_{11}\left(X_{1}, t\right)=\frac{1}{W_{3}} \int_{0}^{W_{3}} \varepsilon_{11}\left(X_{1}, X_{3}, t\right) d X_{3}$

On the other hand, the non-parametric method gives the uni-axial Cauchy (true) stress field: $\Sigma_{11}\left(X_{1}, t\right)$. Therefore, we can measure stress-strain relation at any point of the specimen. As assumed at the beginning of this section, the stress-strain relation should not vary from point to point.

The proposed error measurement will be based on the variation of the stress-strain relation from point to point. For any point $X_{1}$, we have $\varepsilon_{11}\left(X_{1}, t\right)$ and $\Sigma_{11}\left(X_{1}, t\right)$. Therefore, we can write:

$\Sigma_{11}=\mathrm{R}\left(X_{1}, \varepsilon_{11}\right)$

Let $\bar{\Sigma}_{11}\left(\mathrm{E}_{11}\right)$ be the average stress-strain relation. It reads:

$\bar{\Sigma}_{11}\left(\mathrm{E}_{11}\right)=\frac{1}{L} \int_{0}^{L} \mathrm{R}\left(X_{1}, \varepsilon_{11}\right) d X_{1}$

We should note that the average stress-strain relation is only defined for $\varepsilon_{11}<\varepsilon_{0}$ where $\varepsilon_{0}$ the lowest strain achieved by all points in the specimen. Subsequently, the error measurement is defined as:

$\Xi=\sqrt{\frac{\int_{0}^{\mathrm{E}_{0}} \int_{0}^{L}\left|\mathrm{R}\left(X_{1}, \varepsilon_{11}\right)-\bar{\Sigma}_{11}\left(\varepsilon_{11}\right)\right| d X_{1} d \varepsilon_{11}}{\int_{0}^{\mathrm{E}_{0}} \int_{0}^{L}\left|\bar{\Sigma}_{11}\left(\varepsilon_{11}\right)\right| d X_{1} d \varepsilon_{11}}}$

\subsection{Results}

Firstly, we should note that stresses and strains are negative in compression experiments. However, we choose to plot their absolute values in this section.

In Fig. 4 , we plot, the Cauchy (true) stress, $\Sigma_{11}$, as function of time in four points of the specimen. These results are obtained by the non-parametric method from the boundary force and the 2D displacement and strain fields. In Fig. 4(a), (b) and (c), we are interested in results of a quasi-static, intermediate and high strain rate test, respectively. The quasi-static test is clearly homogeneous. On the other hand, the high strain rate stress field is clearly heterogeneous. The intermediate strain rate stress field is in between.

Furthermore, we plot the strain field obtained by the DIC technique Fig. 5. The heterogeneity of the strain field has the same tendency as stress heterogeneity.

These observations are confirmed by Fig. 6(a) where we plot stress homogeneity coefficient $\left(\alpha_{\sigma_{11}}(t)\right)$ defined by Eq. (10). The strain homogeneity coefficient $\left(\alpha_{\varepsilon_{11}}(t)\right)$, determined by Eq. (11), is also plotted in Fig. 6(b). Both coefficients have the same tendency. They are lower than $5 \%$ for quasi-static tests and higher than $5 \%$ for intermediate and high strain rate tests. This confirms that the assumption of stress and strain homogeneity at intermediate and high strain rates is not valid for this rubber.

In Fig. 7, we plot the stress-strain relations at 4 points of the specimen for the three strain rate ranges. We superimpose the average stress-strain relation of all points in the same plot. The stress-strain relations at quasi-static and intermediate strain rates are almost independent of the point on the specimen, which indicates that the stress field obtained at these two strain rates is highly accurate. The errors (see Table 1 ) are 0.84 and $1.81 \%$ for the quasi-static and medium strain rate, respectively. Fig. 7(c) shows stress-strain curves obtained by the high strain rate test.

There is slight variation from point to point. As the tested material is homogeneous, this indicates that there exist some errors. Indeed, the local-polynamial differentiation method adopted in this work has a filtering effect on
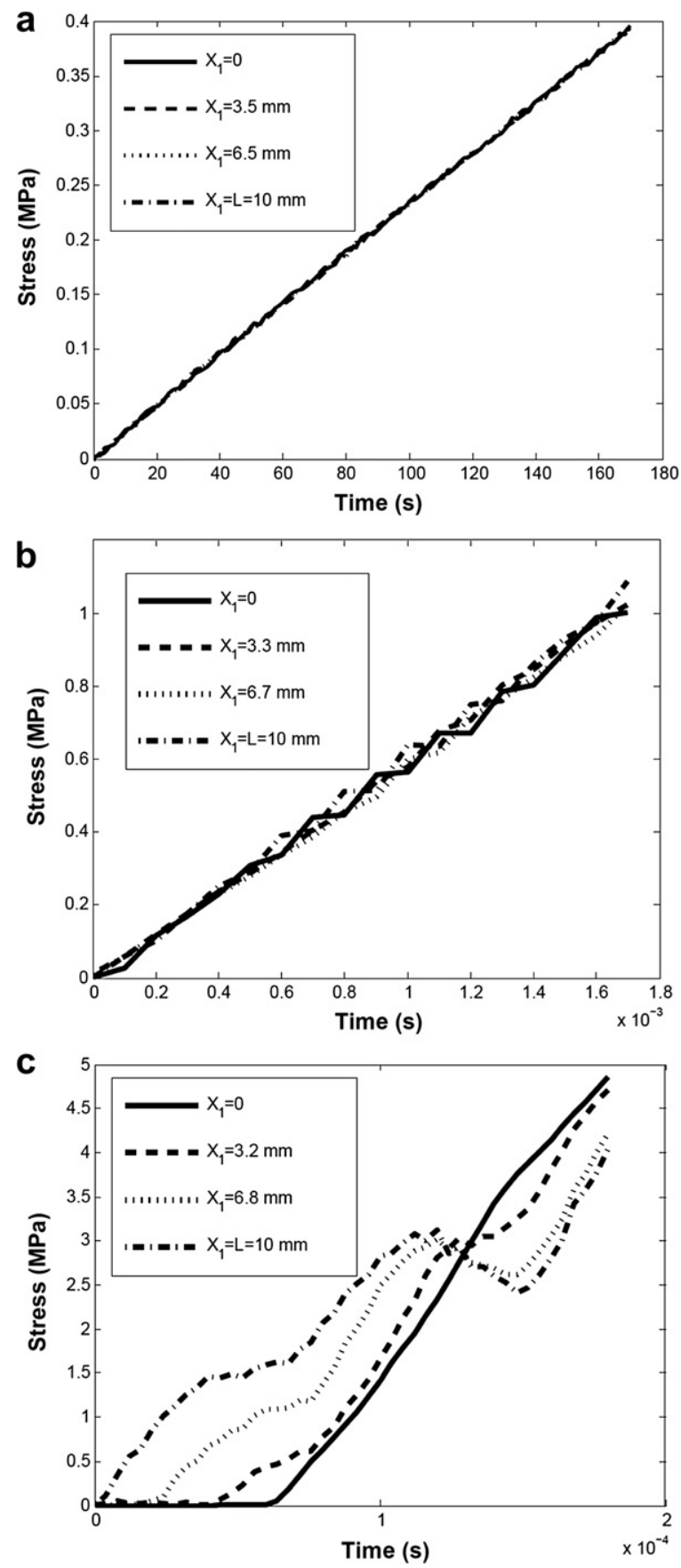

Fig. 4. Stress in four points obtained by the non-parametric method: (a) quasi-static strain rate, (b) intermediate strain rate, (c) high strain rate. 

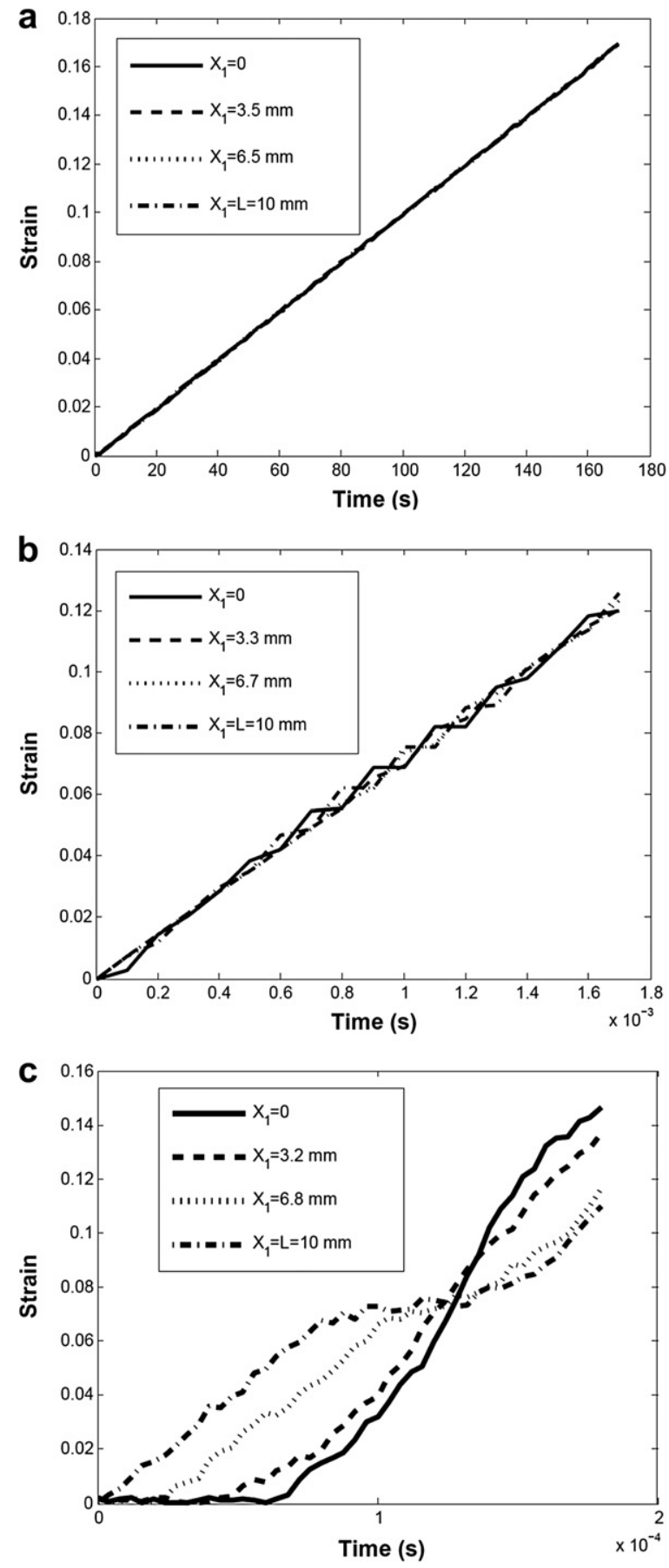

Fig. 5. Strain in four points obtained by DIC technique: (a) quasi-static strain rate, (b) intermediate strain rate, (c) high strain rate.

the measured displacement field. On one hand, an overfiltering eliminates inertia effects which are important to the calculation of the force gradient. On the other hand, a sub-filtering does not eliminate noise which can be amplified by the differentiation method. At high strain rate, this yields a higher but acceptable error, namely, 5.17\% (Table 1 ).
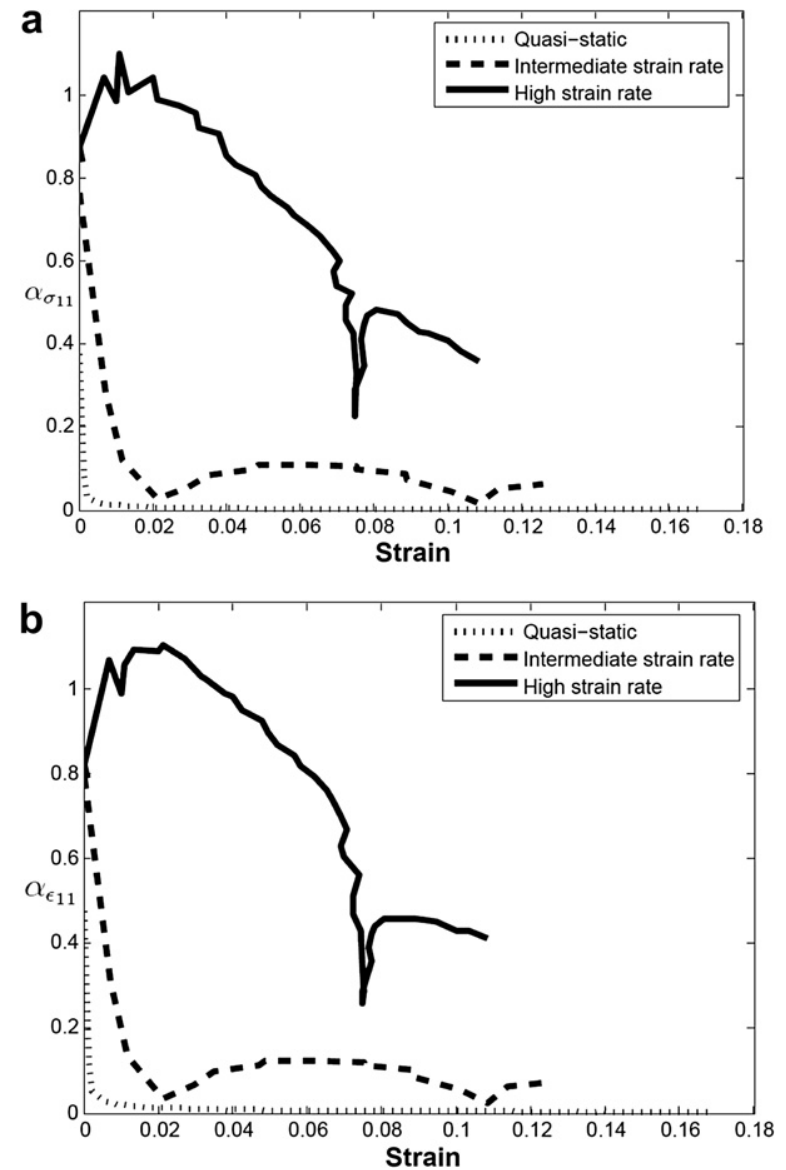

Fig. 6. Homogeneity coefficients as function of the mean strain: (a) $\alpha_{\sigma_{11}}(t)$, (b) $\alpha_{\varepsilon_{11}}(t)$

Furthermore, we compare in Fig. 8 the proposed nonparametric method with the conventional method which assumes stress and strain homogeneity in the specimen. Precisely, we plot in this figure the average stress-strain relations obtained at three strain rates by the nonparametric method. We superimpose in the same figure the stress-strain relations obtained with the conventional method, i.e., the stress and the strain obtained from a force and a displacement, respectively, measurement at the boundary. At quasi-static and intermediate strain rate, we obtained almost the same relation. However, the stressstrain relation obtained at high strain rate by the conventional method is clearly wrong. This confirms once more the relevance of the non-parametric method proposed in this paper.

\section{Discussion}

The non-parametric method developed in this paper is a powerful and alternative solution to inverse techniques. The main advantage of this method is that it takes into account stress heterogeneity without assuming any a priori knowledge of a constitutive equation. The authors are convinced that the non-parametric method will open an 

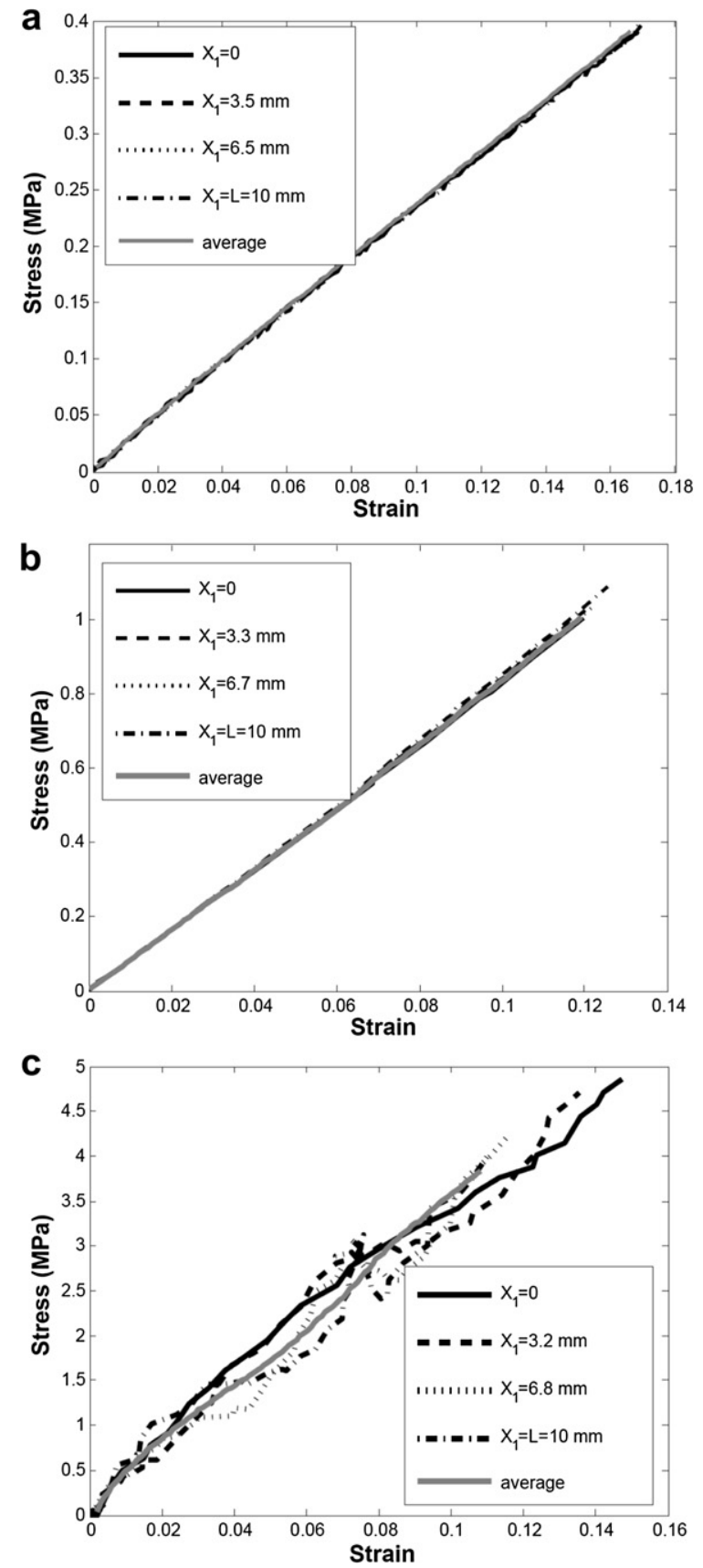

Fig. 7. Stress-strain relation in four points and the average stress-strain relation: (a) quasi-static strain rate, (b) intermediate strain rate, (c) high strain rate.

application field for DIC techniques in measuring stress field in heterogeneous dynamic experiments. It is, therefore, possible to carry out high strain rate tests on soft materials and obtain accurate stress-strain relations. This technique could be used for several dynamic setups; for example, Taylor impact experiments.

The main limitation of the non-parametric method is the double numerical differentiation in order to infer axial acceleration from displacement measurement. This
Table 1

Errors of the non-parametric method at different strain rates.

\begin{tabular}{llll}
\hline & Quasi-static & Intermediate strain rate & High strain rate \\
\hline$\Xi(\%)$ & 0.84 & 1.81 & 5.17 \\
\hline
\end{tabular}

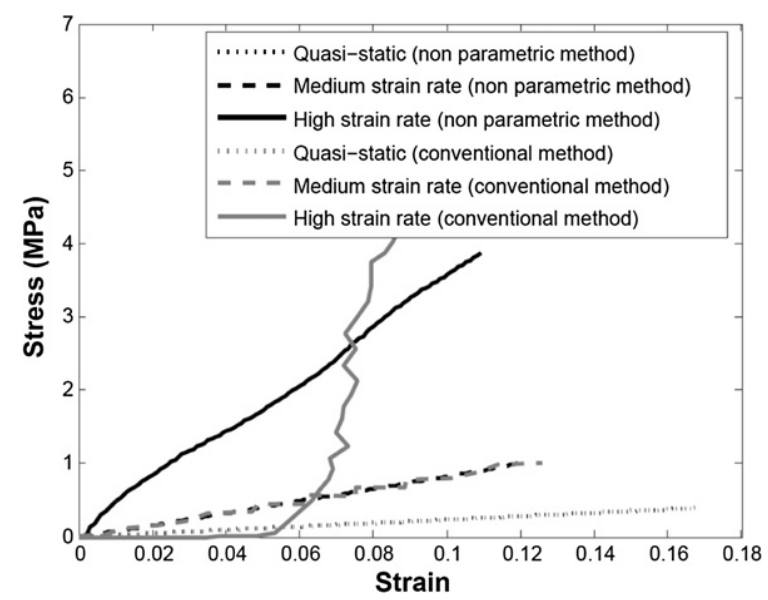

Fig. 8. The average stress-strain relations at different strain rates.

numerical differentiation may amplify experimental noise. Whatever the differentiation technique, a suitable filtering should be used. Strong filtering may filter inertia effects and the stress field will be homogeneous; on the contrary, weak filtering does not eliminate noise. Although the numerical differentiation is a real problem for the nonparametric method, the results obtained by this method have good accuracy. The obtained stress-strain relations are more accurate than those obtained by a conventional technique assuming dynamic equilibrium. In order to check further the accuracy of the non-parametric method, one can measure force at the two specimen sides and then apply Eq. (5) to calculate one force (let's say at $X_{1}=L$ ) from the force measured at $X_{1}=0$. An error measure of the nonparametric method will be the difference between the measured and calculated forces at $X_{1}=L$.

In this work, we were interested in identifying the Cauchy (true) stress field. To achieve this task, the force applied at any cross-section of the specimen is divided by the current cross-section area. If the Piola-Kirchoff (nominal) stress field is of interest, the identified force had to be identified by the initial cross-section area of the specimen, which is a simpler task, as we do not need to compute the variation of the cross-section area during the test.

\section{Conclusions}

In this paper, we developed a non-parametric method for stress field identification in high strain rate experiments. It is based on a force measurement at one specimen boundary and a displacement measurement by a digital image correlation technique. This method is applied successfully to a synthetic rubber. This technique allows deduction of the stress-strain relation at any point of the specimen, and is more accurate than the conventional method assuming dynamic equilibrium. 


\section{Acknowledgements}

The Region Pays de la Loire (France) is highly acknowledged for the financial support to the second author. Furthermore, the authors would like to thank P. Guégan and F. Pasco (Ecole Centrale de Nantes) for their help in the experimental work.

\section{References}

[1] S. Diot, D. Guines, A. Gavrus, E. Ragneau, Two-step procedure for identification of metal behavior from dynamic compression tests. Int. J. Impact Eng. 34 (2007) 1163-1184.

[2] X. Xiao, Dynamic tensile testing of plastic materials. Polym. Test. 27 (2008) 164-178.

[3] R. Othman, P. Guégan, G. Challita, F. Pasco, D. Lebreton, A modified servo-hydraulic machine for testing at intermediate strain rates. Int. J. Impact Eng. 36 (2009) 460-467.

[4] J.L. Ruiz-Herrero, M.A. Rodrýguez-Pérez, J.A. de Saja, Design and construction of an instrumented falling weight impact tester to characterise polymer-based foams. Polym. Test. 24 (2005) 641-647.

[5] B.A. Gama, S.L. Lopatnikov, J.W. Gillespie Jr., Hopkinson bar experimental technique: a critical review. Appl. Mech. Rev. 57 (2004) 223-250.

[6] W. Chen, F. Lu, M. Cheng, Tension and compression tests of two polymers under quasistatic and dynamic loading. Polym. Test 21 (2002) 113-121.

[7] S. Ouellet, D. Cronin, M. Worswick, Compressive response of polymeric foams under quasi-static, medium and high strain rate conditions. Polym. Test. 25 (2006) 731-743.

[8] N.K. Naik, Y. Perla, Mechanical behaviour of acrylic under high strain rate tensile loading. Polym. Test. 27 (2008) 504-512.

[9] H. Zhao, Testing of polymeric foams at high and medium strain rates. Polym. Test. 16 (1997) 507-516.

[10] H. Zhao, G. Gary, A new method for the separation of waves. Application to the SHPB technique for an unlimited duration of measurement. J. Mech. Phys. Solids 45 (1997) 1185-1202.

[11] R. Othman, M.N. Bussac, P. Collet, G. Gary, Testing with SHPB from quasi-static to dynamic strain rates. J. Phys. IV 110 (2003) 397-402.

[12] R. Othman, G. Gary, Testing aluminum alloy from quasi-static to dynamic strain-rates with a modified Split Hopkinson Bar method. Exper. Mech. 47 (2007) 295 \{299.

[13] J.E. Field, S.M. Walley, W.G. Proud, H.T. Goldrein, C.R. Siviour, Review of experimental techniques for high rate deformation and shock studies. Int. J. Impact Eng. 30 (2004) 725-755.

[14] G. Gary, Comportement dynamique des métaux à grande vitesse de déformation. Modélisation, Techniques de l'Ingénieur BM 7 (176) (2001) 1-10.

[15] H. Zhao, G. Gary, Étude expérimentale du comportement dynamique des matériaux. Mécanique \& Industries 1 (2000) 15-26.

[16] S. Aloui, R. Othman, A. Poitou, P. Guégan, S. El-Borgi, Non-parametric identification of the non-homogeneous stress in high strain-rate uni-axial experiments. Mech. Res. Comm. 35 (2008) 392-397.

[17] G. Challita, R. Othman, Finite-element analysis of SHPB tests on double-lap adhesive joints. Int. J. Adhes. Adhes. (2010) 236-244.

[18] H. Meng, Q.M. Li, Correlation between the accuracy of a SHPB test and the stress uniformity based on numerical experiments. Int. J. Impact Eng. 28 (2003) 537-555.

[19] B. Song, W. Chen, Dynamic stress equilibration in split Hopkinson pressure bar tests on soft materials. Exper. Mech. 44 (2004) 300-312.

[20] L.M. Yang, V.P.W. Shim, An analysis of stress uniformity in split Hopkinson bar test specimens. Int. J. Impact Eng. 31 (2005) 129-150.
[21] L. Hong, X. Li, X. Liu, Z. Zhou, Z. Ye, T. Yin, Stress uniformity process of specimens in SHPB test under different loading conditions of rectangular and half-sine input waves. Trans. Tianjin Univ. 14 (2008) 346 450-456.

[22] S.S. Sarva, S. Deschanel, M.C. Boyce, W. Chen, Stress-strain behavior 348 of a polyurea and polyurethane from low to high strain rates. Polymer 349 (48) (2007) 2208-2213.

[23] D.J. Frew, M.J. Forrestal, W. Chen, pulse shaping techniques for testing Elastic-plastic materials with a split Hopkinson pressure bar. Exper. Mech. 45 (2005) 186-195.

[24] K.S. Vecchio, F. Jiang, Improved pulse shaping to achieve constant strain rate and stress equilibrium in split-Hopkinson pressure bar testing. Metal. Mater. Trans. 38A (2007) 2655.

[25] U. Zencker, R. Clos, Limiting conditions for compression testing of flat specimens in the split Hopkinson pressure bar. Exper. Mech. 39 (1999) 343-348.

[26] H. Zhao, G. Gary, Crushing behaviour of aluminium honeycomb under impact loading. Int. J. Impact Eng. 21 (1998) 827-836.

[27] S. Pattofatto, A. Poitou, H. Tsitsiris, H. Zhao, A new testing method to investigate the compacting behaviour of fresh concretes under impact loading. Exper. Mech. 46 (2006) 377-386.

[28] C.M. Roland, J.N. Twigg, Y. Vu, P.H. Mott, High strain rate mechanical behavior of polyurea. Polymer 48 (2007) 574-578.

[29] J. Shim, D. Mohr, Using split Hopkinson pressure bars to perform large strain compression tests on polyurea at low, intermediate and high strain rates. Int. J. Impact Eng. 36 (2009) 1116-1127.

[30] P. Guégan, R. Othman, D. Lebreton, F. Pasco, N. Swiergiel, P. Thevenet, Experimental investigation of rubber ball impacts on aluminium plates, Int. J. Crashworthiness, in press, doi:10.1080/ 13588260903504044.

[31] Special issue: inverse problems in experimental Mechanics. Exper. Mech. 48 (4) (2008) 379-569.

[32] G. Gary, H. Zhao, Dépouillement de l'essai aux barres de Hopkinson par une technique de calcul inverse. J. Phys. IV C8 (1994) 89-94.

[33] L. Rota, Application des méthodes inverses au dépouillement de l'essai aux barres de Hopkinson Ph.D. Thesis. Ecole Polytechnique, France, 1997.

[34] H. Zhao, Material behaviour characterisation using SHPB techniques, tests and simulations. Comput. Struct. 81 (2003) 1301-1310.

[35] J. Kajberg, G. Lindvist, Characterisation of materials subjected to large strain rates by inverse modelling based on in-plane displacement fields. Int. J. Solids Struct. 41 (2004) 3439-3459.

[36] J. Kajberg, B. Wikman, Viscoplastic parameter estimation by high strain-rate experiments and inverse modelling - speckle measurements and high-speed photography. Int. J. Solids Struct. 44 (2007) 145-164.

[37] M. Sasso, G. Newaz, D. Amodio, Material characterization at high strain rate by Hopkinson bar tests and finite element optimization. Mater. Sci. Eng. A 487 (2008) 289-300.

[38] S. Mousavi, K. Welch, U. Valdek, B. Lundberg, Non-equilibrium split Hopkinson pressure bar procedure for non-parametric identification of complex modulus. Int. J. Impact Eng. 31 (2005) 1133-1155.

[39] Y. Guetari, P. Guégan, A. Poitou, an experimental investigation of orthogonal cutting advanced measurement techniques and machinability aspects. Int. J. Forming Process 9 (2006) 473-489.

[40] J.R. Klepaczko, An experimental technique for shear testing at high and very high strain rates - the case of mild-steel. Int. J. Impact Eng. 15 (1994) 25-39.

[41] H. Zhao, S. Abdennadher, R. Othman, An experimental study of square tube crushing under impact loading using a modified large scale SHPB. Int. J. Impact Eng. 32 (2006) 1174-1189.

[42] H. Zhao, G. Gary, J.R. Klepaczko, On the use of a viscoelastic split Hopkinson pressure bar. Int. J. Impact Eng. 19 (1997) 319-330.

[43] W. Chen, B. Zhang, M.J. Forrestal, A split Hopkinson bar technique for low-impedance materials. Exper. Mech. 39 (1999) 80-85.

[44] R. Othman, R.H. Blanc, M.N. Bussac, P. Collet, G. Gary, Identification de la relation de dispersion dans les barres. C.R. Mécanique 320 (2002) 849-855. 